\author{
ÓSCAR ORTEGA GARCÍA* \\ JAMES RODRÍGUEZ CALLE ${ }^{* *}$ \\ MARITZA MONTAÑO ${ }^{* * *}$ \\ Universidad Icesi (Cali, Colombia)
}

\title{
Aspectos generales de un modelo de oralidad en la Universidad Icesi ${ }^{* * * *}$
}

\author{
Generals Aspects of an Orality Model in Icesi University
}

\author{
Aspectos gerais de um modelo de oralidade \\ na Universidade Icesi
}

\footnotetext{
* Docente del Departamento de Lenguaje y Coordinador del Área de Oralidad, en la Universidad Icesi. Magíster en Literatura Latinomaericana (Universidad del Valle) y Magíster en Derechos Humanos y Cultura de Paz (Universidad Javeriana - Cali). Correo electrónico: oscorte@gmail.com

${ }^{* *}$ Docente de Comunicación Oral y Escrita, en la Universidad Icesi. Estudiante del doctorado en literatura latinoamericana y Magister en estudios de la cultura con mención en literatura hispanoamericana, de la Universidad andina Simón Bolívar, sede Ecuador. Correo electrónico: jamesroca@gmail.com

*** Maritza Montaño González realizó estudios de pregrado en Filosofía, es Magíster en Literatura Colombiana y Latinoamericana de la Universidad del Valle y Master of Arts in Hispanic Studies de The University of British Columbia. Es docente del Departamento de Lenguaje de la Universidad Icesi, Cali. Correo electrónico: maritza@interchange.ubc.ca

**** Este artículo se inscribe a la investigación Diseño de un Modelo de Laboratorio de Oralidad para Investigación en el Aula y Divulgación de Experiencias Significativas de Icesi. Este proyecto fue aprobado en convocatorio interna de la Universidad Icesi en octubre de 2014 y fue realizado durante todo el 2015. Artículo de investigación recibido el 04/09/2015 y aceptado el 17/12/2015.
} 


\section{Cómo citar}

Ortega García, O.; RodríGuez CALle, J. y Montaño, M. (2016). Aspectos generales de un modelo de oralidad en la Universidad Icesi. Revista CS, no. 18, pp. 183-210. Cali, Colombia: Facultad de Derecho y Ciencias Sociales, Universidad Icesi. 


\section{Resumen}

Abstract

Resumo

El siguiente informe de investigación presenta los resultados obtenidos durante las fases de indagación, recopilación y propuesta de creación de un modelo de oralidad de la Universidad Icesi. De acuerdo con el modelo aristotélico de retórica, el documento está dividido en cinco momentos: 1. Inventio: cuenta el proceso de cómo se llega a establecer la necesidad de un modelo de oralidad en la Universidad Icesi, con los antecedentes del proceso de consulta. 2. Dispositio, las fases en las que se pensó el proceso, incluyendo la implementación vislumbrada. 3. Elocutio (desarrollo-argumentación): toda la disposición teórica, que no pierde de vista las plataformas revisadas. 4. Actio: una caracterización pormenorizada de las puestas en escena (el modelo Perpet). 5. Mneme: conclusiones.

\section{PALABRAS CLAVE:}

Oralidad | Prosaica | Retórica | Dramática | Significación | Sentido

This research report presents the results gathered during the stages of inquiry, compilation, and proposal of an orality model unique to Icesi University. The document is divided into five sections that make use of the Aristotelean rhetorical model: 1 . Inventio: summarizes the process of establishing the need of an oral expression model for the Icesi university, including early stage research. 2. Dispositio: reviews the steps of the proposed model. 3. Elocutio: presents the theoretical background for the model. 4. Actio: a detailed characterization of the real world performance of the model. 5. Mneme: Conclusions.

\section{KEYWORDS:}

Orality | Prosaic | Rhetoric | Dramatic | Signification | Sense

O seguinte relatório de pesquisa apresenta os resultados obtidos durante as fases de indagação, recopilação e proposta de criação de um modelo de oralidade da Universidade Icesi. De acordo com o modelo aristotélico de retórica, o documento está dividido em cinco momentos: 1. Inventio: conta o processo de como se chega a estabelecer a necessidade de um modelo de oralidade na Universidade Icesi, com os antecedentes do processo de 
consulta. 2. Dispositio, as fases nas que se pensou o processo, incluindo a implementação vislumbrada. 3. Elocutio (desenvolvimento-argumentação): toda a disposição teórica, que não perde de vista as plataformas revisadas. 4. Actio: uma caracterização pormenorizada das encenações (o modelo Perpet). 5. Mneme: conclusões.

\section{PALAVRAS CHAVES:}

Oralidade | Prosaica | Retórica | Dramática | Significação | Sentido 


\section{Inventio (¿Cómo nació la idea?)}

Todo empieza con la palabra. El sonido de la voz materializa el pensamiento y lo traduce con la ayuda de un código, que suele ser colectivo. En casi todas las actividades sociales interviene la oralidad: aprendizajes, transacciones, conflictos, acuerdos; de ahí que se tenga la impresión de que es la oralidad la que permite el éxito o determina el fracaso en el desempeño de las acciones interpersonales (Instituto Cervantes, 2008). En la mayoría de actos comunicativos cotidianos media el lenguaje oral, y este se convierte en una suerte de "tesoro universal" en el que casi todos colaboramos "espontáneamente en su conservación" (Bourdieu, 2001: 19).

El lenguaje como construcción colectiva y colaborativa sufre mutaciones, alteraciones y transgresiones en la cotidianidad. Por ello, desde la academia algunos manifiestan su preocupación por conservar tanto la palabra hablada como la escrita en una urna que no permita la intromisión de daños o innovaciones non sanctas. En muchas instituciones académicas se repite constantemente la queja: "no hablamos ni escribimos bien". Y en el mundo empresarial, el reclamo es similar. En ámbitos como el jurídico ya se habla del desprestigio de la oralidad (Nieva Fenoll, 2010: 245).

En la universidad, las conferencias, exposiciones, debates o la simple participación en clase motivan el desarrollo de estrategias de comunicación oral que permitan cautivar la atención y lograr la comprensión de las ideas expresadas. El mundo político de los estudiantes enfrenta la constante apertura de sus fronteras, lo que permite el acceso a diversas formas de pensamiento. Así, contemplando la misión de la Universidad Icesi de aprender para "conocer y actuar para construir un mundo mejor" (Universidad Icesi, 2013), la oralidad no sólo es posible sino necesaria.

Ante este panorama y con la intención de iniciar la discusión para crear un Modelo de Oralidad en la Universidad Icesi (MOI), en 2013 el director del Departamento de Lenguajes y Comunicación, Hoover Delgado, invitó a un grupo de profesores para pensar estrategias que fortalecieran las competencias comunicativas y argumentativas de los estudiantes. Así, los integrantes del Seminario de oralidad ${ }^{1}$ formulamos varias preguntas: ¿qué es hablar bien?, ¿qué hace una persona cuando habla bien?, ¿cuáles son las condiciones para hablar bien?, ¿existe una convención social para hablar en público?, ¿qué importancia tiene el conocimiento para la oralidad?, ¿se necesita ser experto para hablar en público?, ¿existe algún registro superior que sirva como modelo

1. El Seminario de oralidad está integrado por Hoover Delgado, jefe del Departamento de Lenguaje de la Escuela de Ciencias de la Educación; Óscar Ortega García, coordinador del Área de Oralidad, del Departamento de Lenguaje; Armando Muñoz, James Rodríguez y Maritza Montaño, profesores del mismo departamento. Se realizan reuniones semanales, de dos horas. Maritza Montaño se integró al seminario en el segundo semestre de 2015 y colaboró ampliamente con la redacción del presente informe. 
para la oralidad?, ¿de qué forma se disfraza el estudiante para ser comprendido?, ¿qué papel desempeña la comunicación en la subjetividad? A éstas han seguido otras que mencionaremos más adelante.

\section{¿Por dónde empezamos?}

Al seminario fue invitada la profesora María Isabel Echavarría, quien compartió su experiencia sobre exposiciones orales, conferencias, discursos y demás, mientras cursó su doctorado en administración de la salud en la Universidad de Washington, EE. UU. Echavarría nos presentó tres tipos de experiencia de exposiciones orales:

a. "Las de puro texto": con diapositivas recargadas de citas textuales, que interferían entre el público y el expositor. Según la docente, esta era una práctica "muy latina”.

b. "Las de sólo imágenes": con diapositivas que sólo presentaban imágenes, fotografías, caricaturas o representaciones visuales, en las que la intervención se centraba en contar o explicar determinado concepto o experiencia a partir de la imagen. En este caso, los oradores solían ser "muy efectivos".

c. "Las que tenían teatralidad": algunos expositores sustentaban su exposición en la expresión oral y en los recursos de la teatralidad (ubicación en el espacio, movimientos corporales, gestos, expresiones, pausas...). En este caso, los oradores "atrapaban la atención del público".

Echavarría señaló algo muy importante para nosotros: "La mayoría de los expositores, sobre todo los que fueron muy efectivos, utilizaron un libreto" (Seminario de oralidad, 2014). Es ya bien sabido que la palabra escrita moldea la oralidad (Ong, 1997), pero consideramos que la rigurosidad de un libreto no es desarrollada en las aulas de una universidad.

A partir de esa conversación nos propusimos recopilar las diferentes experiencias en oralidad que tuvieran cabida en los ámbitos académicos, empresariales y de impacto social. A continuación, presentamos las diferentes experiencias en oralidad recopiladas en el curso de esta investigación. Estas experiencias fueron escogidas por su repercusión académica, empresarial y social, medida en el número de visitantes a sus respectivos sitios web o suscriptores en los canales del portal Youtube. Además, determinamos dos categorías para la ficha de análisis: qué hace, en términos operativos, y quiénes participan, detallando tanto el público como los oradores. Estos fueron los hallazgos: 


\section{Experiencias de oralidad en la academia}

\section{University of Oxford Podcast}

Contiene las diferentes actividades académicas que realizan en esta universidad: conferencias, clases magistrales, material de enseñanza, charlas y entrevistas con académicos destacados. El material de audio y video está organizado en la página web en tres secciones: Personas, Departamentos y Escuelas y Series. También hay un enlace llamado Aprendizaje abierto, dirigido a docentes e investigadores que deseen utilizar los materiales para sus clases.

Los archivos pueden descargarse de manera fácil y gratuita, pues portan licencias de Creative Commons ${ }^{2}$. De acuerdo con la información suministrada en su página oficial, University of Oxford Podcast cuenta con "más de 6.500 artículos organizados en 416 series" y ha publicado el trabajo de más de 4.780 colaboradores académicos (University of Oxford, 2011). Además, en octubre de 2008 se lanzó el sitio de podcast en $I$ Tunes $U$, desde donde pueden descargarse gratuitamente los materiales de audio y video y reproducirse en aparatos electrónicos móviles. Ya se han realizado 21.5 millones de descargas desde este sitio paralelo. Los administradores de la web calculan que se han reproducido cerca de 5.500 horas de material, se han presentado 4.780 oradores académicos y colaborados (University of Oxford, 2011).

Si bien los números impresionan, cabe anotar que Oxford no establece un modelo o línea para estandarizar sus materiales. De hecho, algunas clases magistrales son grabadas sin ninguna consideración técnica (cámaras, micrófonos, edición, etc.) ni restricción de tiempo.

\section{Harvard Thinks Big}

En septiembre de 2005, la Universidad de Harvard creó su canal oficial en Youtube para compartir grabaciones de conferencias, entrevistas y clases magistrales de sus profesores más destacados. Los videos están clasificados de acuerdo a las doce escuelas y a los cinco institutos que funcionan en sus campus (Cambridge y Boston, MA).

En la actualidad, este canal ha logrado 242.094 suscriptores y 34.916.271 reproducciones, cifras que claramente se leen como un elevado nivel de influencia entre sus usuarios. Los materiales no tienen un estándar técnico ni consideraciones temporales; pero los videos más recientes tienen menor duración (doce minutos en promedio) y mejor calidad de sonido.

2. "Creative commons es un proyecto internacional que tiene como propósito fortalecer a creadores para que sean ellos mismos quienes definan los términos en que sus obras pueden ser usadas, qué derechos desean entregar y en qué condiciones lo harán” (Organización Creative Commons Colombia, 2006). 
Sin embargo, lo que realmente nos llamó la atención para esta investigación fue Harvard Thinks Big: un evento que reúne a algunos de los más renombrados miembros de las facultades de la universidad para hablar a los estudiantes de pregrado. Este evento toma prestado el modelo creado por Conferencias TED para que los profesores destacados presenten durante un tiempo límite de diez minutos algo que los apasiona, inspira o trascienda.

El objetivo de las conferencias de Harvard Thinks Big es mostrar a los estudiantes de pregrado "una amplia gama de 'grandes ideas' para que no se limiten a escuchar lo contrario ('pequeñas ideas')" (The President and Fellows of Harvard College, 2011).

\section{MIT Lab Media}

El Massachusetts Institute of Technology creó, en 1985, el MIT Lab Media para promover alianzas entre áreas de investigación tradicionalmente distantes entre sí. "The Lab está comprometido a mirar más allá de lo obvio, a hacer las preguntas cuyas respuestas podrían mejorar radicalmente la manera de vivir, aprender, expresarse, trabajar y jugar" (MIT Lab Media).

La pestaña titulada Events contiene el archivo de conferencias, coloquios, seminarios, charlas y defensas de tesis de grado desde 1995. Los videos no tienen restricciones para descargar o compartir, aunque no exhiben licencias de Creative Commons. Las presentaciones carecen de rigor técnico, aunque la calidad de la imagen y del sonido sean buenas. Existe una categoría especial que reúne las charlas de especialistas (investigadores, profesores, profesionales destacados, estudiantes, etc.) de Conversations Series, un evento periódico y popular en redes sociales. El canal MIT Lab Media en Youtube, creado en octubre de 2007, tiene 9.653 suscriptores y sus videos se han reproducido 2.706.133 veces.

\section{MIT Open Course Ware}

Si bien el canal de MIT Lab Media tiene una gran difusión en Internet, no se compara con el canal MIT Open Course Ware, creado en Youtube en octubre de 2005, que tiene 757.320 suscriptores y 70.437.745 reproducciones. En la página del MIT Open Course Ware, el Instituto plantea su compromiso con la generación, difusión y preservación de conocimiento, y el trabajo colaborativo que permita influir en los grandes desafíos del mundo. MIT ofrece a sus estudiantes una educación compuesta de estudio académico riguroso y emoción de descubrimiento, apoyada por una comunidad universitaria diversa que busca desarrollar en cada miembro la capacidad y la pasión para trabajar prudente, creativa y efectivamente en el mejoramiento de la humanidad (MIT Open Course Ware, 2005). 
La idea de "liberar conocimiento" nació en el año 2000 y fue apoyada por el Comité de Facultades de la Universidad de Harvard. Esta es otra posibilidad que podríamos trabajar en el Modelo de Oralidad Icesi, la difusión gratuita de materiales académicos (syllabus, talleres, exámenes, exposiciones, clases), pues el valor agregado que alcanza no sólo dentro de la comunidad estudiantil propia, sino foránea, rompe con cualquier presupuesto de socialización.

\section{Experiencias de oralidad en ámbitos sociales:}

\section{$\underline{\text { TED Conferences }}$}

El éxito que tiene TED en el mundo podría radicar en la simplicidad con que producen eventos para difundir "ideas inspiradoras", lo cual logra acercar a las audiencias. En Youtube, TED Talks ha reunido 3.701 .188 suscriptores, 12 canales de videos y 64.448 videos que han tenido 446.732 .412 reproducciones, desde su inicio en diciembre de 2006. Sin duda alguna, es la experiencia en oralidad con mayor impacto en el mundo.

TED nació en 1984, como un evento donde expertos en Tecnología, Entretenimiento y Diseño compartirían con un auditorio experiencias y logros "inspiradores". Actualmente, se presenta como una comunidad global, que acoge a personas de todas las disciplinas y culturas, en su intento de comprender el mundo y difundir ideas que generen cambios (TED, 2014).

Pero TED no es un modelo de oralidad, sino un evento en el que la oralidad goza de un prestigio elevado. El formato es de ritmo rápido: en una semana se realizan 50 o más conversaciones, de aproximadamente 18 minutos cada una.

Este evento tiene otros paralelos: TEDActive, TEDGlobal, TEDWomen, TEDYouth y TEDCity2.o. También acoge eventos más cortos, como TED Salones, eventos de nocheyTED@, en el que se explora un tema de interés y se comparte a través de las redes sociales. La difusión de los videos, en la mayoría de casos, es gratuita, pero tiene un complejo sistema de derechos de autor y propiedad intelectual especificados en su página web.

\section{The Moth}

Es una empresa dedicada a contar historias. El equipo de The Moth se ocupa de "trabajar con cada narrador para encontrar la historia, darle forma y presentarla" (The Moth, 2007). Nació en 1997, como un solitario evento en un restaurante de Nueva York, cuando su creador, George Dawes Green, presentó una historia que resultó divertida y amena para los asistentes. Hoy, esta empresa ha logrado reunir a miles de narradores (anónimos y famosos) y, gracias a la diversificación de sus productos, se convirtió en 
un referente cultural de Nueva York, aunque también se ha extendido a otras ciudades de Estados Unidos.

El evento más popular es The Moth Show. En este, un grupo de narradores sigue el temario propuesto por los administradores; a menudo logran historias inesperadas, siempre muy humanas y auténticas. "Los espectáculos de danza entre el documental y el teatro, acompañan la creación de una experiencia única, íntima y, muchas veces, instructiva para el público (...) Además, disuelven las barreras socio-económicas, exponen las vulnerabilidades y en silencio sugieren formas de superar retos y ver con nuevos ojos" (The Moth, 2007).

Gracias al reconocimiento alcanzado, en los últimos años varias empresas se han aliado con The Moth para crear "programas corporativos", en los que se desarrollan los siete principios de esta compañía para satisfacer necesidades específicas: trabajo en equipo, habilidades para presentaciones orales, perfeccionamiento del discurso, avanzar hacia nuevos conceptos, empresa e identidad (proyecto), historia de la marca y liderazgo ejecutivo. Estos logros de The Moth son interesantes para nuestro proyecto, su experiencia servirá para la construcción del MOI, pues nuestra intención es abrir las puertas de la Universidad Icesi para que el conocimiento fluya y trascienda.

\section{Experiencias de oralidad en ámbitos empresariales}

\section{Ignite}

Ignite es un formato de exposición en público, que limita la presentación a usar sólo 20 slides, por 15 segundos cada una, para un total de 5 minutos. Esto obliga al orador a sincronizar su discurso con lo que muestra en la pantalla y a ir directo al punto central de la charla. Desde su inicio (2006), Ignite ha organizado más de cincuenta eventos, en los que participan voluntariamente cientos de personas. Con las restricciones ya descritas, se presentan historias de temas variados, pero con un fin particular: servir como fuente de inspiración.

El lema, "Que ilumine, pero que sea rápido", obliga a que todo sea medido con exactitud para lograr el objetivo planeado. Por ello, se ha estimado que en una intervención se utilizan en promedio 160 palabras por minuto, alrededor de 40 palabras por diapositiva, para un total de 800 palabras. Todo debe ser medido.

\section{Pecha Kucha}

Es un estilo de presentación en el que se muestran 20 diapositivas durante 20 segundos cada una, para un total de 6 minutos y 40 segundos. Este formato obliga a centrar una idea principal con elocuencia y claridad. El evento Pecha Kucha Night nació en febrero 
de 2003, para que jóvenes diseñadores pudieran reunirse, mostrar sus creaciones e intercambiar ideas. Poco a poco, el formato se fue compartiendo y en mayo de 2014, este espectáculo ya se había celebrado en más de 700 ciudades en el mundo. Aunque no hay mayores restricciones para realizar Pecha Kucha Night en cualquier lugar del mundo, sí es obligatorio solicitar permiso para conceder ciertos derechos a los creadores de esta marca y modelo de presentación oral.

\section{Dispositio (¿Qué pensamos hacer?)}

La búsqueda de diferentes estrategias orales y formatos de exposición en público, nos dispuso a encontrar un punto de equilibrio entre lo argumentativo y lo comunicativo. Pareciera existir una frontera entre ambos aspectos, toda vez que se consideraba que lo primero era logrado en un texto escrito, mientras que lo segundo hacía parte de asuntos menores a la hora de defender una idea. Es decir, al rigor académico con el que se escribía un documento ensayístico debía ahora agregarse lo narrativo para alcanzar una sustentación apropiada del tema desarrollado.

Tradicionalmente el curso Comunicación Oral y Escrita $\mathrm{II}^{3}$ implicaba el desarrollo de un texto con características argumentativas, en el que se defendía un punto de vista sobre un tema escogido de manera libre por cada estudiante. Ese texto sería la base para iniciar el trabajo de oralidad con el que los participantes de estos cursos fortalecían sus competencias argumentativas y comunicativas. Así se empezó a fraguar el modelo Perpet, que implica la preparación, ensayo, grabación y afinamiento de una presentación en público, bajo la mirada de una puesta en escena, y se relaciona con el concepto de storytelling, gracias al vínculo inminente entre escritura y oralidad establecido en el Seminario de Oralidad.

El storytelling es la representación de una puesta en escena, esto es, una narración. En el libro Storytelling, la máquina de fabricar historias y formatear las mentes (Salmon, 2008) se define como una técnica de comunicación que ha mutado hasta convertirse en una política de empresa, con un sinnúmero de aplicaciones (cambios institucionales, implementación de un nuevo producto, la redefinición de una marca, etc.). La profesora Teresa Gordillo, al reseñar el libro de Salmon, da valor a esta práctica porque "las historias forman parte de la estructura mental de los individuos, (...) es gracias a dicha estructura que la práctica del storytelling ha dado grandes resultados a nivel empresarial" (Gordillo, 2010: 89).

3. Una vez presentado, discutido y debatido en diferentes ámbitos académicos de la Universidad Icesi nuestra propuesta de modelo de oralidad, este curso sufrió un cambio considerable: de 48 horas semestrales pasó a 64 horas, para darle cabida a la oralidad, aspecto que no se consideraba a pesar del nombre. 
Aunque las bondades del uso del storytelling son evidentes, también existen inconvenientes a considerar en términos narrativos. "Cuando una historia oral relatada a menudo no es narrada de hecho, lo único que de ella existe en ciertos seres humanos es el potencial de contarla. Nosotros (los que leemos textos como este) por lo general estamos tan habituados a la lectura que rara vez nos sentimos bien en una situación en la cual la articulación verbal tenga tan poca semejanza con una cosa, como sucede en la tradición oral" (Ong, 1997).

Esto nos lleva a reconocer que hay dos componentes de la expresión oral: lo dicho, es decir, los elementos que harán parte del desarrollo temático de la presentación, y su puesta en escena, compuesta por todo lo que existe alrededor de lo dicho. Paul Ricoeur (1996) amplía esta diferenciación cuando afirma que un discurso es un evento (algo que ocurre cuando alguien habla), pero también es significación (en tanto dice algo).

\section{El modelo Perpet}

La sigla Perpet corresponde a Preparación, Energía, Respiración, Público, Espacio y Técnica. Se trata de un modelo (pedagógico, no mediático aún) que sintetiza los hallazgos metodológicos del profesor Delgado, y algunos profesores que lo hemos acompañado, para lograr una puesta en escena prestigiosa, efectiva y eficiente. Esta metodología de trabajo constituye la base del Modelo de Oralidad propuesto a la Universidad Icesi. Representa el punto diferenciador a la hora de asumir la oralidad en la academia, puesto que no atiende los aspectos propios de la comunicación como algo meramente técnico sino como fundamentales al momento de compartir conocimiento.

Una vez los estudiantes escriben el documento tipo ensayístico (y cumplen con la primera parte del MOI, el inventio), deben concentrar la atención en la puesta en escena de la sustentación oral de este trabajo. Así, los procesos de comunicación de los que debe ocuparse el orador son:

\section{Preparación}

Corresponde en primer lugar a la disposición (dispositio) de la puesta en escena, bajo la estructura de un plan de oralidad. Aquí se recurre a la estructura clásica en cuatro momentos: exordio, narratio, demostratio y epílogo. En el exordio, el orador estructura su saludo, la presentación del tema y de su idea central, además de esgrimir un gancho con el que pretende captar la atención del público (puede ser con una pregunta retórica, una cifra impactante o una anécdota personal (Donovan, 2013). La creatividad se pone en juego, además de la sensibilidad del estudiante, porque deberá lograr que los datos alcanzados en la investigación realizada para la elaboración del texto escrito se fusionen de una manera cálida con los asistentes a la exposición. Un buen gancho, que no debe 
superar los cuarenta segundos ${ }^{4}$, garantiza la atención en lo que se dirá en el siguiente paso, la narratio. Llega el momento de la exposición de los argumentos: la distribución clara y concreta de los datos (cifras, voces, frases, anécdotas, etc.) debe ir en concordancia con la idea central ya expresada. Se evita caer en repeticiones innecesarias o argumentos poco sólidos. El tiempo estimado para este momento oscila entre los dos y los cuatro minutos 5 . El tercer momento es la demostratio, en el que se expone la conclusión del tema. Aunque pueda parecer extraño, algunos oradores concluyen con una idea diferente a la expuesta en el exordio, lo cual crea confusión entre el público. Nuestra recomendación es que se sinteticen las ideas secundarias dispuestas en la narratio y reiteren la idea central; de esta manera, los espectadores podrán recordar fácilmente la idea que está sustentando el orador. Entre veinte y cuarenta segundos es el tiempo estimado para una conclusión sintética. Por último, está el epílogo, que no es igual a la conclusión. El orador debe dejar a su auditorio con una reflexión emanada de una pregunta o con el cierre de la anécdota con la que inició su discurso.

La preparación también incluye el ensayo de la estructura dispuesta en el plan de oralidad. En el modelo de oralidad de la Universidad Icesi se contempla las técnicas del espejo, del tape and ape (con una grabadora de voz), el uso del video o la exposición ante un grupo. Para los integrantes del Seminario de Oralidad, la técnica más apropiada en la del video, pues permite observar y oír aspectos que a simple vista no se perciben. En términos didácticos, cada estudiante que asiste al curso de Comunicación Oral y Escrita II recibe un diagnóstico de sus presentaciones con base en una rejilla de evaluación de cuatro aspectos: estructura de la presentación, lenguaje, lenguaje no verbal y material de soporte (diapositivas u objetos).

\section{Energía}

Para el momento de la puesta en escena (actio), el orador se ocupa del control de su contacto visual, usando una mirada que genere una interacción adecuada con el auditorio (las miradas se clasifican en una taxonomía). Sin caer en la instrumentalización de la comunicación, el contacto visual del orador con el auditorio podría representar, en algunos casos, ganancia o pérdida de la credibilidad, algo fundamental para la defensa de una idea. De igual manera, se inscribe en el ámbito de la energía el contacto gestual: los asentimientos, deícticos, gestos básicos (principalmente con las manos y brazos) y los ilustradores de subrayado forman parte del carácter argumentativo de la presentación.

4. En promedio, las sustentaciones realizadas en el curso de Comunicación Oral y Escrita II oscilan entre los tres y los cinco minutos.

5. El tiempo se calcula con base en el número de palabras escritas para el exordio. Por supuesto, se adecúa de acuerdo al tiempo disponible para toda la presentación. 
Reconocer cómo se mira y qué gestos se utilizan durante una exposición constituye una verdadera revelación para los estudiantes, pues pocas veces algún profesor se detiene en estos aspectos, quizás porque los considera irrelevantes dado que privilegia "el contenido". El modelo de oralidad propuesto enfoca su atención en la estructura de la presentación pero también en los ítems del lenguaje no verbal.

\section{Respiración}

El cuerpo se controla a través de la respiración. La toma de conciencia del acto de respirar determina el flujo de las palabras y, con esta, la claridad en la sustentación de una idea central. La respiración suele ser el signo evidente del famoso pánico escénico, una característica casi común a todos los estudiantes. Con algunos ejercicios de toma, contención y expulsión del oxígeno, se busca lograr la respiración diafragmática, que logra la capacidad total de los pulmones. Por supuesto, no es fácil, pero la concienciación del acto de respirar puede traducirse en una puesta en escena contundente y clara, esto es un discurso libre de muletillas y con pausas significativas.

\section{Público}

Una puesta en escena contempla un público. Durante los ensayos y ejercicios dispuestos en el curso de Comunicación Oral y Escrita II se hace una constante reflexión sobre el objetivo de la presentación, que no lo alcanza el orador sino el auditorio. Por ejemplo, tratándose de una sustentación argumentativa, el objetivo podría estar en términos de convencer o persuadir al público de la idea central, bien sea que la logre incorporar como propia o cambie su parecer respecto al tema tratado en la exposición.

Durante el tiempo dedicado a la oralidad, los estudiantes refinan este aspecto con base en respuestas a preguntas del tipo ¿a quién se habla? o ¿quiénes conforman el auditorio? También, a partir de técnicas para interactuar adecuadamente, como inspirar confianza al auditorio en los primeros minutos, detectar los posibles focos de distracción y la preparación de las preguntas, que pueden aparecer durante la exposición o al final de la misma.

\section{Espacio}

El orador también prepara los tipos de espacio, de tal suerte que sepa moverse en el auditorio o detenerse en un punto para concentrar la atención. La disposición del espacio puede representar tropiezos en la estructura, ya que el orador podría ubicarse en un punto donde su voz pierde proyección o la manera como se encuentra ubicado el público resulta incómoda para comprender el mensaje. Así, pues, durante el curso logramos conocer que existen escenarios a la italiana (clásico y con calles, como un salón de clases tradicional), en círculo, en $\mathrm{U}$, en forma de espina de pescado (típico de los laboratorios de Icesi), en anfiteatro (como algunos auditorios) y la mesa de trabajo. 


\section{Técnica}

En este último aspecto del modelo Perpet se ajustan los componentes propios de las tecnologías de la palabra, como la proyección de la voz, la resonancia, la articulación, la dicción, el tono, la tonalidad y la entonación. Algunos ejercicios propuestos a los estudiantes están ligados a la imitación de voces, la lectura en voz alta y representación con visos de teatralidad de una escena de alguna seria televisiva. La técnica es el último eslabón de la cadena y, sin duda, de mayor complejidad debido a la cantidad de componentes que alberga. Además, de la conexión natural con los demás aspectos, tal como lo hemos mencionado.

El modelo Perpet es la segunda parte del curso Comunicación Oral y Escrita II, con una duración de 32 horas semestrales (en total, el curso tiene 64 horas). Como se trató de una reestructuración en el diseño del curso, quisimos que los profesores que regularmente dictaban este curso vivieran la experiencia de sustentar una idea con base en el MOI. El taller terminó de diseñarse en abril de 2014 y se impartió a los profesores en el mes de mayo. En cada sesión se realizaron simulacros de clases y el derrotero que se cumplió fue el siguiente:

\section{Día 1}

Ejercicio de improvisación para la discusión posterior sobre la pertinencia de un tema que pueda ser abordado en un límite de tiempo. Diálogo sobre cómo la memoria y la imaginación intervienen en el desarrollo de los discursos (inventio). Exposición acerca de la necesidad de establecer un plan de escritura (dispositio y elocutio) para realizar una micro clase. El plan debía contener estos elementos: tema, objetivo, idea central y acciones.

\section{Día 2}

Cada profesor entregó su plan de escritura y realizó la exposición de la micro clase, que fue grabada en video. Después, hicimos un diagnóstico en el que comparamos el plan de escritura, lo que se llevó a escena y lo que se logró medir en la plantilla de evaluación oral. En la socialización del diagnóstico surgió la necesidad de involucrar al público o audiencia dentro del plan. Este fue un cambio significativo, porque en un evento oral no sólo se debe considerar al orador y el discurso-texto, también al público, que debe ser incorporado en tres momentos de inmersión: cercana, con el ensayo; directa, con la puesta en escena, y lejana, con la retroalimentación posterior. La planeación, entonces, cobra sentido completo con la inmersión retroalimentadora (lo que Aristóteles llama Mneme, es decir, la idea de la construcción de la memoria no como técnica, sino como proceso).

\section{Día 3}

La reflexión sobre el papel de la escritura en la oralidad permitió presentar el desarrollo de la estructura de la puesta en escena: exordio (presentación de la exposición, donde 
se plantea el tema, objetivo e idea central); narratio (disposición de los elementos que serán expuestos); demostratio (disposición de los argumentos que intervendrán en la exposición, así como la presentación de la conclusión); y epílogo (final o cierre). Convino recordar los elementos de la oratoria clásica que aparecen en Retórica, de Aristóteles: Inventio, Dispositio, Elocutio, Actio, Mneme. Los cuatro elementos de la estructura del discurso oral corresponden a la dispositio, organización espacio temporal del discurso.

\section{Días 4 Y 5}

El lenguaje no verbal fue el tema principal de estas sesiones. Aspectos acerca de la mirada y del gesto sirvieron para comprender que en la puesta en escena intervienen otros elementos que influyen en la comprensión del discurso.

El taller con los profesores sirvió para reelaborar el programa del curso Comunicación Oral y Escrita II. Consideramos que, con ligeras modificaciones, este modelo podría replicarse a los profesores que deseen convertir sus cursos tradicionales en Cursos $O$ (con énfasis en el desarrollo de competencias en oralidad).

\section{Elocutio \\ (¿En qué nos basamos?)}

El MOI retoma construcciones teóricas de diversas tradiciones, que ya han sido implementadas en nuestras aulas de clase, en distintas experiencias pedagógicas y en todos los niveles de enseñanza. Además de la revisión de plataformas existentes, hemos sintetizado un número de herramientas que permiten seguir refinando nuestra metodología para las emisiones propias de la comunicación en público. Una tarea que incluye recoger elementos del Modelo Semántico Comunicativo desarrollado en Icesi (Oviedo, 2002), pero que exige estudiar profundamente otros lenguajes no verbales.

A continuación, referiremos algunos presupuestos que enmarcan teórica y metodológicamente, la definición, los alcances y las particularidades de una propuesta de oralidad propia de la Universidad Icesi para los medios digitales de comunicación.

En primer lugar, la oralidad, como se entiende en este proyecto, hace parte de la construcción de expresiones y discursos prestigiosos dentro del contexto académico y organizacional. Esto implica que nos ocupamos de lenguajes intervenidos por las "tecnologías de la palabra" y, principalmente, por la "tecnología de la escritura" (Ong, 1997: 60-62) ${ }^{6}$; pues los emisores ideales en los que hemos estado pensando serían

6. Entre otras implicaciones de la tecnología de la escritura, para Ong: "Las personas que han interiorizado la escritura no sólo escriben, sino también hablan con la influencia de aquélla; [la cultura oral por el contrario] no maneja conceptos tales como las figuras geométricas, categorización por abstracción, procesos de razonamiento formalmente lógicos, definiciones, o aun descripciones globales" Para un cuestionamiento de esta postura, con fines más antropológicos que lingüísticos, ver Vich y Zavala (2004). 
autoridades, preferiblemente académicas, en los temas expuestos; o innovadores, en el caso del mundo organizacional y empresarial (sin dejar de lado otros discursos, también prestigiosos en ámbitos sociales más amplios).

Además del prestigio en términos expresivos y de autoridad, otro criterio general es el de efectividad de los discursos orales. Por este se hace necesario pensar nuestro tema más allá de los presupuestos verbales, pues la comunicación actual es rica en recursos expresivos, que además ya no son privativos de las industrias mediáticas y de los grandes medios de comunicación. ${ }^{7}$

Al inicio de la Teoría de la acción comunicativa, Habermas se refiere al saber en dos sentidos: uno, el más convencional, tiene que ver con la capacidad de lenguaje y su correspondiente expresión a través de una estructura proposicional (en la racionalidad del ser humano): "En las emisiones o manifestaciones lingüísticas se expresa explícitamente un saber". El otro tendría que ver con la expresión de "una capacidad, un saber implícito", al que Habermas llama la acción teleológica. A línea seguida aclara que: este "Know how puede en principio tomar la forma de un know that". Cuando hablamos de prestigio en la oralidad, nos referimos a una capacidad de lenguaje, a un Know that. Pero para alcanzar efectividad es necesario construir la capacidad, el Know how. En este sentido, buscamos estrategias para que el saber académico se complemente con un saber comunicacional (Habermas, I, 1999: 24). ${ }^{8}$

\section{La estesis, además de la semiosis}

Otra perspectiva importante es la propuesta de disciplina que Katya Mandoki llama prosaica. Como una crítica a la estética y a la historia del arte (eurocentristas), confina sus objetos de estudio más tradicionales a una rama de la socioestética que denomina poética, a la cual pertenecen los procesos de producción y recepción de las artes. De otro lado, en la rama de la socioestética que nos interesa, estarían las prácticas de producción y recepción estética en la vida cotidiana" la prosaica "médica, escolar, familiar, religiosa, militar, nacional, jurídica [política, esotérica], deportiva, artística [...] (Mandoki, 2006 II: 16-21).9

Cabe señalar que la autora ha denunciado la "fetichización del objeto estético" y de la obra de arte y ha propuesto entender la estética como proceso de estesis, es decir, como: "sensibilidad o condición de abertura o permeabilidad del sujeto al contexto en que está inmerso" (Mandoki, 2006 II: 15). Con esto, su propuesta se hace importante para nosotros en tanto que se alinea con la apuesta de entender la oralidad como un proceso que se enfatiza en el sujeto y lo que hace en un discurso

7. Como es el caso de la fotografía y sus desarrollos en dispositivos móviles (Bañuelos y Mata, 2014).

8. Concepción similar a la de evento y significación, de Ricoeur (1996).

9. La prosaica artística corresponde al arte visto como práctica social en la vida cotidiana. 
oral (como enunciador o enunciatario) y no solamente en la obra o en el lenguaje, como haría una propuesta estructuralista.

Para aclarar la idea, en palabras de Mandoki: "no es el arte, ni la obra o la forma lo que expresa, sino el artista, igual que no es el lenguaje el que significa [y comunica] sino el sujeto que lo articula. El arte no es expresión de emociones; es el espectador quien percibe e interpreta una expresión de emociones y genera otras a partir de su propia experiencia con tal objeto" (Mandoki, 2006 II: 21). Como dijimos, efectividad es uno de los criterios principales que rigen este proyecto. Podríamos agregarle también, eficiencia, pues no se trata sólo de lograr el objetivo comunicativo, sino de hacerlo a partir de un formato ágil y pertinente para cada evento o proyecto.

Sin reducir el valor o la precisión semántica ni perder el rigor de los oradores, creemos posible configurar tipologías (eventos/formatos) que lleguen de forma adecuada a los auditorios. Por tal razón, el criterio de prestigioso no puede confundirse simplemente con un valor de la poética, de la (convencionalmente) llamada estética, como ya aclaramos. No se trata de producción o recepción de arte, aunque nos valgamos de elementos de la dramaturgia o de la literatura. Se trata de proponer una comunicación que parta del discurso prestigioso, pero además divulgue ideas en el contexto exigente de las nuevas tecnologías de la información y la comunicación.

El MOI que proponemos se sustenta en un plan que supera la concepción meramente lingüística de los significados y las significaciones. La eficacia, la eficiencia e incluso el prestigio del discurso oral dependen de una conjugación de diversos elementos comunicativos. Podemos pensarlo, por lo pronto, como dramática y retórica, en el plano de la enunciación, o como estesis y semiosis a un mismo tiempo, en el plano de la significación (Mandoki, 2006 II). En el siguiente apartado nos ocuparemos con más detenimiento de los registros de la retórica y de las modalidades de la dramática que propone la autora y que hemos tomado como herramientas importantes para nuestra propuesta de modelo de oralidad.

\section{Oralidad como Performance o la Performatividad como metodología}

Para demarcar el modelo en términos dramáticos ${ }^{10}$, es preciso aclarar, con Poyatos, que "es difícil hablar de hablante, ya que se trata de hablante-actor, pues considerado el sistema comunicativo interpersonal en su totalidad, se actúa, no se habla sólo" (1970: 734). Como este autor, varios teóricos coinciden en pensar la oralidad en términos prestados de las artes dramáticas, a partir de los cuales podemos proponer apuestas metodológicas. Es el caso de Lienhard (1992) y también de Vich y Zavala (2004), quienes, pensando en una metodología etnográfica, proponen que un texto o evento oral 
se debería interpretar en tanto que Performance, pues: "la oralidad no sólo es un texto; es un evento, una performance, y al estudiarla siempre debemos hacer referencia a un determinado tipo de interacción social [...] una práctica, una experiencia que se realiza y un evento del que se participa" (Vich y Zavala, 2004: 11).

Las implicaciones de esta afirmación serían similares a los retos de un director de arte dramático que ajusta la eficiencia, la eficacia y el prestigio de su puesta en escena para ese contexto artístico: "todos los discursos orales tienen un significado no sólo por las imágenes que contienen, sino, además, por el modo en que se producen, por la circunstancia en que se inscriben y por el público al que se dirigen" (Vich y Zavala: 2014:11). En ese sentido, hablaríamos de al menos tres elementos: lo que hace el orador/ actor, el escenario o encuadre que se escoge y el auditorio. Los tres son complejos y por eso les dedicamos especial atención.

En el Seminario de Oralidad, en febrero de 2014, el profesor Hoover Delgado planteó esta cuestión a partir del concepto de performatividad, como una solución compleja frente a los desafíos de quien asume "una tipología de evento oral". Para Delgado, el reto del teatro es "hacer que las cosas se presenten. Y el personaje aparece o no aparece. O aparece con mayor o menor fortalez $a^{11}$ (en la psique o en la memoria del espectador)" (Seminario de oralidad, 2014).

Un ejemplo pertinente de un reto de performatividad lo expuso hablando de la película Ricardo III (1995), del director Richard Locraine y el actor Sir Ian McKellen. Lo primero que advierte el profesor es el reto de la doble representación que significa este texto cinematográfico; pues el personaje histórico es del siglo XV (1452-1485) y la obra de Shakespeare es del siglo XVI (probablemente de 1591 y 1592); sin embargo, la película sitúa la historia en la Segunda Guerra Mundial y convierte a Ricardo III en una especie de Hitler británico. No obstante el desafío, para Delgado, "lo que hace este actor es una readaptación de Ricardo III muy potente. Pues aprovecha el escenario que le proponen para hacer más fuerte el texto shakesperiano". En seguida ilustra su reflexión con el ejemplo de cuando el actor proclama la emblemática línea: "imi reino por un caballo!":

En la Segunda Guerra no se sale a la guerra en caballo; entonces es víctima de un asalto por parte de sus enemigos. Él va junto con los dos soldados en un Jeep artillado. De un momento a otro los derriban y el tipo cae en el fango. Se está levantando del fango y ahí lanza la frase, porque tiene que huir a pie. Entonces justifica de una manera muy fuerte esa frase, porque no hay nada, no hay tanques, no hay aviones, no hay jeeps: 'DDaría mi reino por un caballo!' [dice]. Está muy bien traída y lo que hace el actor es eso: encontrar las excusas para que "eso" [la performatividad] aparezca. ¡En la puesta en escena cotidiana pasa lo mismo! ¡Pasa lo mismo! (Seminario de oralidad, 2014).

11. Con los subrayados, intentamos adaptar los énfasis del discurso oral. 
Es decir, tanto en el teatro como en la vida cotidiana y en el contexto académico, el reto tendría que resolverse o concretarse con el cuidado que se pone a la performatividad, entendida como esa posibilidad de aparecer de una forma adecuada y, por lo tanto, como una conjugación de diversos lenguajes; lo que, evidentemente, es bastante complejo cuando se piensa para una comunicación en público y no para la espontaneidad de la conversación cotidiana y su "falta de estructura prestigiosa" (para otro contexto).

\section{La puesta en escena académica}

Delgado plantea la idea de "puesta en escena como una consideración de orden metodológico" (Seminario de oralidad, 2014). El ejemplo que proponía en ese momento era un Taller de conciliación para estudiantes de Derecho. La performatividad en ese caso estaría configurando la puesta en escena propia de esa instancia jurídica (con su escenario propio, sus actores - en dos bandos-y lo que ellos "hacen" y enuncian para aparecer adecuadamente).

Los asistentes a ese taller se estarían preparando para asumir esa puesta en escena como actores principales dentro de un evento dramático. De igual forma, para la universidad se presenta la necesidad de otras tipologías/eventos: una conferencia, una sustentación de trabajo de grado o una disertación; un debate, un informe y, desde luego, una clase y una exposición oral, entre otras. Los talleres de oralidad que se proponen en la universidad son salidas a la urgencia de responder adecuadamente a estos eventos y formatos. Estamos seguros de que, en condiciones adecuadas, muchos de estos eventos académicos pueden convertirse en eventos mediáticos, presentados en una plataforma virtual de la Universidad Icesi.

Al considerarlos metodológicamente como puestas en escena, y por lo tanto composiciones dramáticas (performativas), en los talleres de oralidad se toman en cuenta cuatro elementos que en conjunto generarían una simbiosis entre la dramática y la retórica y que, convertidos en un estilo propio, en una marca, pueden ser parte del mundo de la comunicación digital. Los aspectos, que explicaremos en el próximo apartado son: "1. Estructura/Organización; 2. Lenguaje verbal; 3. Lenguajes no verbales y 4. Materiales de soporte o ayudas" (Seminario de oralidad, 2014). Cada uno de estos elementos tendría su aplicación y correspondiente evaluación en los textos dramáticos. Pensados como estrategia (metodológica, pedagógica) permitirían lograr el objetivo de presentaciones orales prestigiosas, efectivas y eficientes. El modelo de oralidad retomará estos elementos, en el contexto mediático de una plataforma o canal de comunicación. 


\section{Actio \\ (¿Qué debe suceder en un evento oral de MOI?)}

Enumeramos y explicamos a continuación cada uno de los aspectos que consideramos parte integral de nuestra propuesta:

\section{Estructura/organización}

Como aclaramos con antelación, el modelo de oralidad que proponemos, dados sus propósitos (principalmente de divulgación científica), parte necesariamente de la escritura. Pero también, y por las mismas razones, de la tradición de la retórica. Privilegiamos, por tanto, la estructura clásica -introducción, desarrollo y conclusión-, porque permite la organización clara del mensaje y ofrece, además, la posibilidad de alcanzar el objetivo comunicativo. No obstante, en algunos casos, de acuerdo al tema y a los objetivos de una puesta en escena, podemos optar por otras estructuras (un conversatorio o un panel, por ejemplo). A continuación referimos los pasos de estructuración que han sido probados en los talleres de oralidad de Icesi.

\section{Plan de escritura}

Para decidir sobre la estructura de una puesta en escena, inicialmente proponemos diseñar un plan de escritura; una tecnología de la palabra que permite ordenar el contenido de la puesta en escena. Según Delgado, el plan de escritura debe tener los siguientes elementos: 1. Tema (¿de qué se va a hablar?). 2. Tipo de texto: una forma de determinarlo es pensando "los actos mayores de producción: descripción, narración, razonamiento, argumentación” (Oviedo, 2002:12). Aunque no es infalible ni es la única forma posible, el Storytelling (narración) es uno de los tipos de texto más efectivos en plataformas con propósitos parecidos al que proyectamos. 3. Objetivo: Para Eileen McEntee, quien va a hablar en público debe preguntarse: “¿qué tipo de respuesta quiero en mi público? ¿Qué quiero lograr de mi público con mi intervención? [...] ¿Qué quiero que sepan, piensen o hagan cuando abandonen este salón?" (1996:507); para Delgado, el objetivo “puede ser cognitivo (que conozca, sepa o comprenda), persuasivo (que se adhiera o se convenza), emotivo (que se conmueva)". 4. Idea central: "Todas las ideas son importantes, pero hay una central, que organiza, rige o guía el texto. En rangos de significado, es la idea de más alto precio la que mueve a recordar el texto, con la que se queda el lector y da al mensaje un valor agregado. Se redacta como un breve argumento". 5. Acción textual: "(¿qué hace el texto para alcanzar su objetivo?): Una cosa es lo que dice el autor: otra, lo que hace el texto. El texto explica, defiende, aclara, expone, narra" (Seminario de oralidad, 2014). 


\section{Estructura de la retórica clásica}

A pesar de que al planear un formato oral para un discurso académico es conveniente acudir a la estructuración propia de la escritura, es evidente que, incluso teniendo un guión, sólo se organizan los contenidos en un sentido meramente lingüístico, pero no tenemos lista la puesta en escena (los otros lenguajes). Creemos que la estructura más adecuada para tales efectos es la que se generó en la retórica clásica, pensada en términos que ahora llamamos argumentativos ${ }^{12}$. Está compuesta por los siguientes elementos: 1 . Exordio: presentación que tiene por "objeto excitar la atención y preparar el ánimo de los oyentes" (DRAE, 2001). 2. Narratio: desarrolla la estrategia general del discurso ${ }^{13} \cdot 3$. Demostratio: las conclusiones, en términos argumentativos, no como una finalización. 4. Epílogo: "recapitulación de lo dicho en un discurso [...]" (DRAE, 2001); es también el cierre, la despedida del orador al público. En Icesi, las cuatro partes de una puesta en escena se evalúan según el siguiente criterio: "la estructura de la presentación (introducción, desarrollo del argumento y conclusiones) es coherente, secuencial, y se ajusta al tiempo requerido" (Seminario de oralidad, 2014).

\section{Lenguaje verbal}

Evitando redundar en elementos propios de la comunicación escrita y de la tradición lingüística, que están rigurosamente recogidos en el Modelo Semántico Comunicativo desarrollado por Tito Nelson Oviedo (2002), nos concentraremos en estrategias de comunicación enmarcadas, por un lado, en la propuesta de prosaica, de Katya Mandoki; y, por otro, en la de Fernando Poyatos sobre "paralenguaje, kinésica e interacción" (Poyatos, 1970 y 1994).

Entendidos como estrategias estéticas, para Mandoki los registros de la retórica serían un "quehacer [...] un despliegue para la producción deliberada (consciente o no) de ciertos efectos [...] de credibilidad, autoridad, cariño, simpatía, integración, confianza, ternura, poder... que constituyen el ethos del enunciante y que el destinatario puede conceder, negociar o rehusar" (Mandoki, 2006 II: 29). De los cuatro registros de la retórica que propone Mandoki dos son de lenguaje verbal:

A. El léxico: "[...] ejerce el discurso por medio del material verbal (presentado por sonido de la voz o la imagen del texto) [...y] concierne a lenguajes, jergas o dialectos predominantemente verbales" (Mandoki, 2006 II:33-35). ${ }^{14}$ Sobre este registro, el profesor

12. Compartimos con Mandoki la acepción clásica de Retórica, como "el acto de influir el pensamiento y la conducta del auditorio: es el enunciado persuasivo. [Vamos] a entender por retórica a los medios de persuasión, al arte de mover y con-mover a los otros (en un sentido clásico de oratoria)" (2006: 29).

13. Una de las estrategias más efectivas en varios modelos exitosos es la narrativa: por lo tanto, una de las estrategias sugeridas para un orador tendrá que ser la de adaptar su discurso a la estrategia del Storytelling.

14. A línea seguida, la autora aclara entre paréntesis que "es cuestión de predominio porque hablar implica también 
Oviedo, explicando el Modelo Semántico Comunicativo y hablando de significación y comunicación, dice que "la lengua y, por consiguiente, la significación-comunicación son, además de polifónicas, (en términos de Ducrot) poliscópicas”. Explica además que "las expresiones, en su calidad de signos, pintan un cuadro con pinceladas que proceden de miradas a diversas a 'regiones' de nuestra realidad mental y cultural".

B. El acústico: comprende los sonidos que trascienden la vocalización (las palabras) y que, según Mandoki, constituirían más que un paralenguaje porque no es "sólo paralelo al lenguaje, como complemento, sino propiamente un registro de comunicación con derechos plenos". La autora distingue ocho subregistros acústicos, tomados de Trager (1958:1-12), como "el rango tonal y el control labial de vocalización...” y cuatro categorías de Parret (1995): "volumen (intesidad, gama), movimiento del timbre, continuidad y registro fonatorio" (Mandoki, 2006 II:35-37). Sin embargo, es probable que la taxonomía más rigurosa de los registros acústicos sea la enunciada por Poyatos, en su propuesta de la paralingüistica, que tiene cuatro categorías: cualidades primarias, calificadores, diferenciadores y alternantes (Poyatos, 1970:727-733). Cada categoría está compuesta a su vez por varias cualidades de la comunicación paralingüística (e incluyen los registros enumerados por Mandoki, aunque con distintas denominaciones en algunos casos).

En términos metodológicos y evaluativos generales, para los talleres de comunicación oral de la Universidad Icesi buscamos que el lenguaje verbal en la comunicación oral cumpla con el siguiente presupuesto: "Vocabulario, terminología y estructura de las oraciones apropiado, adecuado, rico y efectivo, cumpliendo además con las normas elementales de corrección, limpieza y claridad del idioma" (Seminario de oralidad, 2014). Para comprobar que este criterio se cumpla, en las matrices de evaluación (retroalimentación) se chequea el registro lexical, la corrección y la claridad de los enunciados, la articulación, los segregados (repeticiones, muletillas y ruidos inadecuados) y el volumen de la voz.

\section{Kinésica, lenguajes no verbales o registro somático de la retórica}

Fernando Poyatos define la kinésica como: "el estudio sistemático de los movimientos corporales no orales, de percepción visual, auditiva o tangible, que aislados o combinados con la estructura lingüística-paralingüística poseen valor expresivo en la comunicación interpersonal" (Poyatos, 1970: 733). Este autor ha generado clasificaciones de los movimientos corporales, de acuerdo a distintos criterios, para complementar "el estudio del sistema comunicativo del español" y contrastarlo con el del inglés, en una tarea que denomina intercultural. 
En una búsqueda similar, Mandoki propone llamar registro somático de la retórica al repertorio de gestos y movimientos corporales no orales; al que le agrega además los subregistros de la "temperatura, olor, talla (para mostrar repudio al contacto físico), humedad (al expresar deseo) e incluso textura (cuando se nos pone la carne de gallina, por ejemplo)" (Mandoki, 2006 II: 38-41). Como resultado de esta propuesta, su lista completa de "subregistros de la retórica somática" sería la siguiente: 1. Postural, 2. Háptico, 3. Térmico, 4. Olfativo, 5. Ocular (tomados de Hall, 1963); además de 6. Hídrico, 7. Gestual, 8. Facial y 9. Volumen o talla (Mandoki, 2006 II: 40-41).

La autora claramente declara la intención de sintetizar las investigaciones que se refieren a body language, facial expressions, kinesics y no verbal communication. Entre muchos autores, resalta los aportes de Edward T. Hall (2003), en proxémica; Birdwhistell (1972), en kinésica y los estudios de Ekman y Friesen (1975) sobre la expresión facial. No obstante, advierte que si se piensa desde la lógica del registro retórico (es decir, desde un despliegue de estrategias previas a la puesta en escena) el término somático sería el más adecuado, puesto que se referiría al "uso retórico del cuerpo [...] para producir efectos de valorización" (Mandoki, 2006 II: 39). Es el eje horizontal de su propuesta (o eje sígnico). Con su propuesta pretende, por tanto, reunir con la categoría registro somático, los lenguajes no verbales y la kinésica.

\section{Las modalidades de la dramática}

Es importante aclarar entonces que la propuesta de prosaica se complementa con lo que Mandoki llama dramática (y sus modalidades): la coordenada de la socioestética que "consiste en actitudes, talante, impulsos y desplantes de energía en la comunicación estética. Es dramática porque el término viene de acción, actuar (...)" (Mandoki, 2006 II: 47-48). Las modalidades son, por lo tanto, los aspectos que permiten estudiar la puesta en escena en tanto que evento, más allá de su estrategia pensada a priori (los registros de la retórica); tiene que ver con la energía proyectada en el diálogo de una puesta en escena. Cada modalidad de la dramática se cruza con un registro de la retórica y es "plenamente dialógica, pues no sólo manifiesta la postura del enunciante, sino su actitud hacia el interlocutor" (Mandoki, 2006 II: 48).

Las modalidades de la dramática son: 1. la proxémica, que evidencia la forma de acercar o alejar al interlocutor (desde cualquiera de los registros); 2. la fluxión, que "abre o cierra el intercambio libre de energía"; 3. la cinética, que "dinamiza o paraliza; agiliza o retarda la interacción" y 4. la enfática, que enfoca en un aspecto en particular. Habría, entonces, proxémica léxica, proxémica acústica, proxémica somática y proxémica escópica; fluxión léxica, fluxión acústica...; y, así, cada registro se cruza con las cuatro modalidades. Aunque no se trata de tomar la prosaica en su totalidad, creemos que la 
propuesta de Mandoki aporta valiosas herramientas metodológicas para el modelo de oralidad de la Universidad Icesi.

Tomando en cuenta las propuestas de Poyatos y Mandoki (y otras que dialogan con éstas), en los talleres de oralidad de Icesi se valoran los lenguajes no verbales con el siguiente criterio (exceptuando el material de soporte que se evalúa como último aspecto): en una puesta en escena efectiva, "los lenguajes no verbales hacen que el expositor demuestre dominio y confianza y que comunique vida y calidez a la presentación" (Seminario de oralidad, 2014).

\section{Materiales de soporte; registro icónico o escópico de la retórica}

En la edición de 1994 de la introducción a su Prosaica, Katya Mandoki proponía llamar registro icónico a "la relación con los objetos como cosas y signos, objetos físicos visibles y tangibles que un sujeto dado utiliza como vestuario, escenografía y utilería para generar enunciados sensibles" (Mandoki, 2006 I: 148-149). Para la edición del 2006 cambió esta denominación por la de escópica ("por el desarrollo que ha tenido la denominación 'icónico' en la semiótica peirciana”); finalmente, sintetiza el registro escópico de la retórica en tres posibilidades de desarrollo: artefactos, imágenes y espacios (Mandoki, 2006 II, 41-42).

Estamos seguros de que, en términos de la experimentación, son enormes las posibilidades que tiene este registro de la retórica para la comunicación en el modelo de oralidad que estamos refinando; en un probable Estudio de Oralidad esto ha de ser posible, muy seguramente ${ }^{15}$. No obstante, por el momento, es evidente que en los ambientes universitarios y organizacionales los artefactos más utilizados para acompañar las presentaciones son las diapositivas (slides). Habría que seguir aportando elementos para un afinamiento que siga convirtiendo esas herramientas en "aliados para expresar con claridad y precisión las ideas [y no] en elementos que, a la hora de la presentación, en lugar de ayudar, muchas veces van en contra de lo que queremos decir y confunden a nuestra audiencia” (Nieto Collazos, 2015).

Por lo pronto, un criterio para evaluar el uso del material de soporte en la Universidad Icesi (construido desde la experimentación pedagógica) es el siguiente: "Los diferentes tipos de materiales de soporte (información cuantitativa y cualitativa) son apropiados, limpios y correctos y respaldan el trabajo del expositor" (Seminario de oralidad, 2014). Las posibilidades del registro escópico ("artefactos, imágenes y espacios") deben ser tomados en cuenta para desarrollos posteriores de esta investigación. 


\section{Mneme: las conclusiones}

El Modelo de Oralidad Icesi es una estrategia para fortalecer las competencias comunicativas y argumentativas de nuestra comunidad académica y pretende llegar a otros ámbitos, como el empresarial y el comunitario, para afianzar el desarrollo de una sociedad deliberativa, participativa y democrática.

Por eso, el MOI combina la concepción del discurso (comunicación con sentido) con la puesta en escena, formando una sola actividad, a la que llamamos expresión oral. Es decir, cada vez que pensemos en una presentación oral (clase, exposición, conferencia, charla, diálogo, entrevista, reunión, seminario, etc.) debemos considerar que no sólo tendremos que afinar un discurso, sino preparar del mismo modo nuestros lenguajes corporal y no verbal, los gestos, las miradas, la energía y la voz, además de los apoyos audiovisuales que requiera el evento.

Para lograr esa preparación óptima, se han revisado rigurosamente las propuestas teóricas más pertinentes (como la proxémica, la quinésica, la prosaica, los lenguajes no verbales...) y se han estudiado y sintetizado en un modelo pedagógico propio de la Universidad Icesi que, por su origen (en las mismas aulas de todos los niveles educativos), responde a nuestros requerimientos de innovación académica, empresarial y tecnológica con altos niveles de calidad.

Cada desarrollo teórico y metodológico investigado ha sido implementado en los distintos cursos y talleres de oralidad que hemos ofrecido en los programas de Icesi (y en algunos proyectos de extensión en el mundo empresarial). Por tal razón, creemos que es viable continuar desarrollando la experimentación pedagógica de la mano del desarrollo del MOI.

Pensar en eventos orales, entonces, supondrá una preparación para la que debemos seguir capacitando a los estudiantes, profesores y personal administrativo de la Universidad Icesi. Ya están en marcha los cursos de Comunicación Oral y Escrita II, así como los talleres a los docentes que los dictan. Pero necesitamos responder a las necesidades en oralidad que los empresarios y la comunidad en general demanden.

Así que la institucionalización de una política de oralidad en la Universidad Icesi se convertirá en un apoyo fundamental para la incorporación, difusión y fortalecimiento del MOI; y es imprescindible si queremos convertirnos en un referente de oralidad visible a partir del diseño y la puesta en marcha de eventos simaleres a las conferencias TED o a los espectáculos de The Moth.

Prevemos que al desarrollar el MOI, convertido en una política institucional, podríamos empezar a planear un evento de características similares a las de TED, o desarrollar estrategias comunicativas a través de la narración, tal como lo hace The Moth. 
Con el MOI, la Universidad Icesi puede aumentar su posicionamiento académico, pues las posibilidades para empezar a crear una comunidad online están a su alcance para virtualizar cursos, diplomados, charlas, conferencias, entre otros eventos orales.

\section{Referencias}

ARISTÓTELES. (2005). El arte de la retórica. Trad. Ignacio Granero. Buenos Aires, Argentina: EUDEBA.

BAÑUELOS, J. \& MATA, F. (2014). Fotografía y dispositivos móviles: escenarios de un nuevo paradigma visual. Monterrey, México: Instituto tecnológico y de estudios superiores.

BOURDIEU, P. (2001). ¿Qué significa hablar? Madrid: Akal.

BUNCE, M. (2014). International news and the image of Africa: new storytellers, new narratives?

En J. Gallagher, The Image of Africa. Manchester: Manchester University Press.

DONOVAN, JEREMY (2012). Método TED para hablar en público. Barcelona: Ariel.

GORDILLO, T. (2010). Reseña al libro Storytelling. La máquina de fabricar y formatear mentes. Revista Comunicación, 89-93.

HABERMAS, J. (1997). Teoría de la acción comunicativa, Vol. 1: Racionalidad de la acción y racionalidad social. Madrid: Taurus.

INSTITUTO CERVANTES. (2008). Saber hablar. Madrid: Aguilar.

LIENHARD, M. (1992). La voz y su huella. Lima: Horizonte.

MANDOKI, K. (2006a). Estética cotidiana y juegos de la cultura: Prosaica 1. México: Siglo Veintiuno.

MANDOKI, K. (2006b). Prácticas estéticas e identidades sociales: Prosaica II. México: Siglo Veintiuno.

MCENTEE, E. (1996). Comunicación oral para el liderazgo en el mundo moderno. México: McGraw-Hill.

MIT LAB MEDIA. (s.f.). About. Recuperado el 8 de Marzo de 2014, de sitio web del MIT Lab Media: http://www.media.mit.edu/about

MIT OPEN COURSE WARE. (11 de Octubre de 2005). About. Recuperado el 18 de Marzo de 2014, de sitio web del canal de videos del MIT Open Course Ware: https://www.youtube.com/user/MIT/about

NIETO COLLAZOS, G. E. (2015). Cómo hacer diapositivas para sus presentaciones. Santiago de Cali: Universidad Icesi.

NIEVA FENOLL, J. (Septiembre- diciembre de 2010). Los problemas de la oralidad. Revista do Ministério Público do RS. (67), 237-257. 
ONG, W. (1997). Oralidad y escritura. Tecnologías de la palabra. México D.F.: Fondo de Cultura Económica.

ORGANIZACIÓN CREATIVE COMMONS COLOMBIA. (22 de Agosto de 2006). ¿Qué es creative commons? Recuperado el 8 de Julio de 2014, de sitio web de la Organización Creative Commons Colombia: http://co.creativecommons.org/?page_id $=672$

OVIEDO ACEVEDO, T. (2002). Abra la boca. Santiago de Cali: Universidad Icesi, Facultad de Derecho y Ciencias Sociales.

OXFORD TALKS. (s.f.). Introducción. Recuperado el 12 de Marzo de 2014, de sitio web de Oxford Talks: http://talks.ox.ac.uk/document/Introduction

POYATOS, FERNANDO. (1970). Paralingüística y kinésica: para una teoría del sistema comunicativo en el hablante español. En Magis, C., editor, Actas del Tercer Congreso Internacional de Hispanistas. México: El Colegio de México

POYATOS, F. (1994). La comunicación no verbal. Madrid: Istmo.

RICOEUR, P. (1996). Tiempo y narración. México D.F.: Siglo XXI.

SALMON, C. (2008). Storytelling, la máquina de fabricar historias y formatear las mentes. Barcelona: Atalaya.

SEMINARIO DE ORALIDAD. (2014). Cuaderno de apuntes del Seminario de Oralidad. Cali.

TED. (s.f.). Attending a TED Conference. Recuperado el 2 de Marzo de 2014, de sitio web de TED : http://www.ted.com/about/conferences

. (s.f.). Our mission: spread ideas. Recuperado el 2 de Marzo de 2014, de sitio web de TED Conferences: http://www.ted.com/about/our-organization

THE MOTH. (2007). About - What is The Moth? Obtenido de sitio web de The Moth: http://themoth. org/about

THE PRESIDENT AND FELLOWS OF HARVARD COLLEGE. (2011). Description of Harvard Think Big. Recuperado el 16 de Marzo de 2014, de sitio web de Harvard Think Big en i Tunes: https:// itunes.apple.com/us/itunes-u/harvard-thinks-big/id424040892?mt=10

UNIVERSIDAD ICESI. (Diciembre de 2013). Proyecto de Desarrollo Institucional al año 2022. Recuperado el 2014 de 8 de Julio, de sitio web de la Universidad Icesi: http://www.icesi.edu.co/ mision_vision_futuro.php

UNIVERSITY OF OXFORD. (2011). Acerca de nosotros. Recuperado el 25 de Marzo de 2014, de sitio web de University of Oxford Postcat: http://podcasts.ox.ac.uk/about

VICH, V. \& Zavala, V. (2004). Oralidad y poder. Herramientas metodológicas. Buenos Aires: Norma. 